\title{
Thermal Quenching in Alpha- and Gamma-Excited Fluorescent Solutions
}

\author{
H. H. Seliger and C. A. Ziegler ${ }^{1}$
}

\begin{abstract}
The effects of reduction of temperature on the relative light outputs of the gas-free liquid scintillators, DPO, $\alpha \mathrm{NPO}$, and $\mathrm{PBD}+\mathrm{POPOP}$, dissolved in xylene, have been investigated. From room temperature down to $-35^{\circ} \mathrm{C}$ the relative light outputs increase markedly under both alpha and gamma excitation. Under the conditions of the present experiments it has been possible to make a gas-free solution of $\mathrm{PBD}+\mathrm{POPOP}$ in xylene more efficient than crystal anthracene.
\end{abstract}

\section{Introduction}

In a previous paper the application of the $4 \pi$ crystal-scintillation counter [1] ${ }^{2}$ to the standardization of the disintegration rates of medium- and highenergy beta emitters was described. The method, however, possesses no advantages over the $4 \pi \beta$-gasproportional counter $[2,3,4]$ in that the method of source preparation is the same and, therefore, the source self-absorption is not changed. The liquidscintillation-counting technique offers a means of completely eliminating source self-absorption because the active material can be incorporated into the solution directly. This is especially important for low-energy beta emitters and electron capturers where source self-absorption can be appreciable [4].

As a first step in the application of liquid scintillators to absolute beta counting it was decided to determine the optimum conditions for maximum light-conversion efficiency of the liquid scintillators. It has been well known in the field of fluorescence that molecular oxygen in solution in an organic fluorescent liquid is in many instances a strong quenching agent $[5,6,7,8,9]$. In 1931 Kautsky [6] showed that the quenching by oxygen of the fluorescence of the dye, trypaflavine, increases as the dye is dissolved in water, alcoholic solutions, and acetonic solutions, corresponding to the increasing solubility of oxygen in these solutions. Seliger, Ziegler, and Jaffe have recently reported [10] that the quenching by oxygen in the cases of DPO and $\alpha \mathrm{NPO}$ in xylene solutions is primarily a solute effect, which appears to be in agreement with results tabulated by $\mathrm{P}$. Pringsheim [11] for other fluorescent solutions. The removal of dissolved oxvgen is, therefore, of primary concern in the improvement of light-conversion efficiency.

A thermal quenching effect for certain fluorescent dyes was also reported by Pringsheim [11]. It was decided to investigate this phenomenon for several of the most efficient liquid scintillators reported $[12,13]$. However, in view of the previous work on oxygen quenching, the thermal quenching was investigated for solutions in which all dissolved gases

Present address: Tracerlab, Inc., Boston, Mass.

2 Figures in brackets indicate the literature references at the end of this paper. had been removed. These included 2,5-diphenyloxazole (DPO); 2-(1-naphthyl)-5-phenyloxazole $(\alpha \mathrm{NPO})$; phenylbiphenyloxadiazole-1,3,4 (PBD); anthracene; and $p$-bis $(2$-(5-phenyloxazolyl $))$-benzene (POPOP).

\section{Experiments and Results}

In previous experiments on the effects of oxygen quenching $[14,15]$ it was reported that relative oxygen quenching was a function of solute concentration. It was therefore decided to measure any possible effects of temperature at concentrations of solute close to the peak light-output concentrations which have been reported by Hayes and co-workers $[12,13]$ at room temperature. The vacuum system that was used to prepare liquid solutions free of all gases is shown in figure 1 . Weighed samples of dry solute were delivered to 5-ml cylindrical Pyrex absorption cells and appropriate volumes of purified $m$-xylene were vacuum distilled into the individual cells, using liquid nitrogen as condensing agent. Each of the cells while still under high vacuum $\left(10^{-5} \mathrm{~mm}\right)$ was flame-sealed from the system. The cells were laid flat on the face of a phototube and were surrounded by an aluminum reflector, the scintillator-phototube combination being inside a light-tight refrigerator. Temperatures were measured by means of a copper-constantan thermocouple in direct contact with the outside of the glass cell.

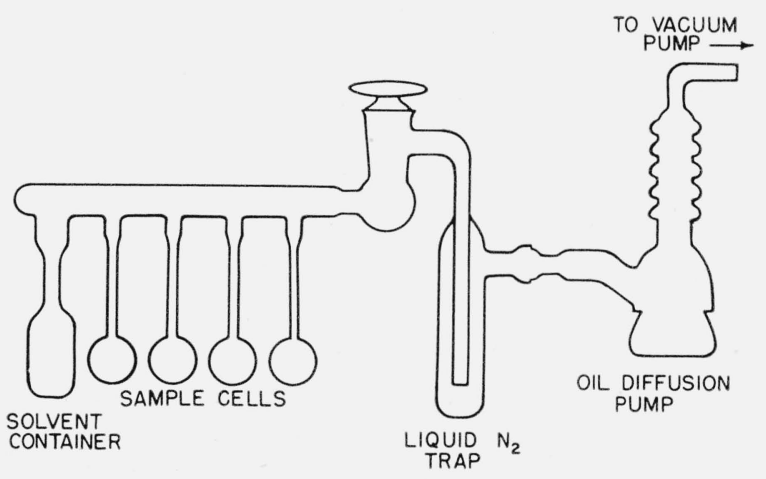

FIGURE 1. Glass system employed for preparing gas-free solutions. 


\subsection{Alpha-Particle Measurements}

In addition to the dry solute, inside each cell was placed a small gold trident on one spear of which was plated sufficient polonium to give 1,000 to 2,000 counts per second. The pulse-height distribution of the source was observed with a single-channel pulseheight analyzer. The change in the light output with temperature was assumed to be proportional to the displacement of the peak position of the pulseheight distribution.

\subsection{Gamma-Ray Measurements}

Sample cells, prepared without the polonium-plated tridents, were placed in the collimated beam of a 1-millicurie radium source. This time the change in the light output with temperature was assumed to be proportional to the $d-c$ current measured with a vibrating-reed electrometer.

The experimentally observed data are summarized in figure 2. The solid curves are the results of the gamma-ray-excitation measurements and the dashed curves are the results of the alpha-particle-excitation measurements. The relative increases observed due to lowered temperatures are of the same order for both alpha and gamma excitation. However, the shapes of the curves are decidedly different. The relative increases in the alpha-excitation case are linear with temperature over the range investigated. The gamma-excitation curves, while exhibiting a steeper initial slope, tend to flatten out somewhat below $0^{\circ} \mathrm{C}$.

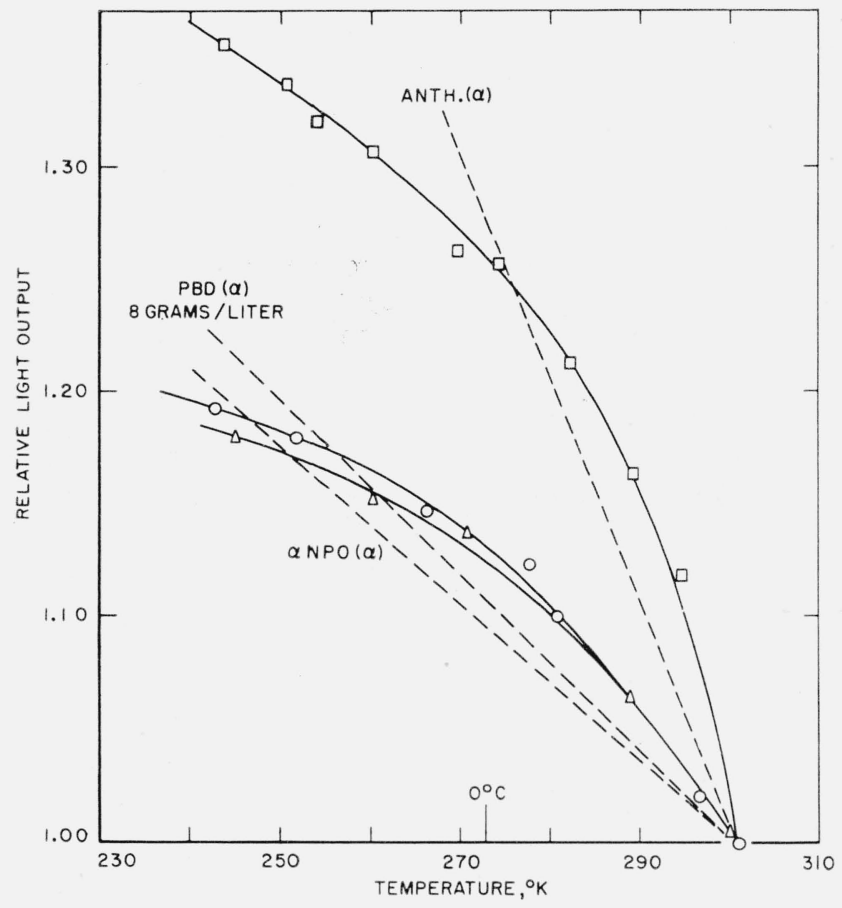

FIGURE 2. Relative light outputs versus temperature for gas-free liquid scintillators.

The dashed curves represent previously obtained data for alpha excitation. The solid curves represent the data for gamma excitation. $\square$, Anthracene $1 \mathrm{~g} /$ liter; 0 , PBD $10 \mathrm{~g} /$ liter+POPOP $2 \mathrm{~g} /$ liter; $\triangle, \alpha \mathrm{NPO} 3.2$ g/liter.

\section{Discussion}

The results reported are for the liquid-scintillatorphototube combination. The phototube temperature response has been investigated previously and was found to decrease slightly with decreasing temperature [16], so that the net increase in liquidscintillator light output would appear to be even greater. However, the phototube effect is small $(0.1$ to $0.2 \%$ per deg C) and seems to vary from one tube to another and with the previous history of the tube.

It is surprising that this effect has not been reported previously, especially as refrigeration is so frequently used in liquid-scintillation counting, to reduce thermal tube noise. However, the increasing solubility of $\mathrm{O}_{2}$ with decreasing temperature gives rise to additional quenching, tending to mask the increase observed with gas-free solutions. Kallmann has measured the light outputs of air-saturated $p$-terphenyl-xylene solutions at room temperature relative to crystal anthracene and reported a ratio of 0.48 [17]. The results of our own gamma-rayexcitation measurements made at room temperature on gas-free PBD + POPOP in xylene and on airsaturated $p$-terphenyl in xylene give a ratio of light outputs of $2.03: 1$. From figure 2 a further factor of 1.20 is to be gained by a temperature reduction of the $\mathrm{PBD}+\mathrm{POPOP}$ solution to $-35^{\circ} \mathrm{C}$. Thus the maximum efficiency obtained in the present experiments for $\mathrm{PBD}+\mathrm{POPOP}$ in xylene w as 1.17 relative to crystal anthracene, the latter at room temperature.

It is intended to extend the measurements described in reference [1] to the liquid scintillator combination of $\mathrm{PBD}+\mathrm{POPOP}$ at reduced temperatures and under gas-free conditions.

\section{References}

[1] C. C. Smith, H. H. Seliger, and J. Steyn, J. Research NBS 5\%, 251 (1956) RP2716.

[2] H. H. Seliger and L. M. Cavallo, J. Research NBS 4\%, 41 (1951) RP2226.

[3] W. B. Mann and H. H. Seliger, J. Research NBS 50, 197 (1953) RP2409

[4] H. H. Seliger and A. Schwebel, Nucleonics (7) 12, 54 (1954)

[5] S. Boudin, J. chim. phys. 27, 285 (1930)

[6] H. Kautsky and R. Eberlein, Chem. Ber. 64, 2677 (1931).

[7] R. W. Pringle, L. D. Black, B. L. Funt, and S. Sobering, Phys. Rev. 92, 1582 (1953).

[8] F. N. Hayes, Los Alamos Report LA-1837, October 1954 (unpublished).

[9] H. Kallmann, U. S. Army Signal Corps Progress Report, February 1955 (unpublished).

[10] H. H. Seliger, C. A. Ziegler, and I. Jaffe, Phys. Rev. 101, 998 (1956).

[11] P. Pringsheim, Fluorescence and Phosphorescence, p. 334 (Interscience Publishers, Inc., New York, N. Y., 1949).

[12] F. N. Hayes, D. G. Ott, V. N. Kerr, and B. S. Rogers, Nucleonics (12) 13, 38 (1955).

[13] F. N. Hayes, D. G. Ott, and V. N. Kerr, Nucleonics 11] 14, 42 (1956).

[14] C. A. Ziegler, H. H. Seliger, and I. Jaffe, Phys. Rev. 99, $663(1955)$.

[15] C. A. Ziegler, H. H. Seliger, and I. Jaffe, Nucleonics (5) 14, 84 (1956)

[16] H. H. Seliger and C. A. Ziegler, Nucleonics [4] 14, 49 (1956).

[17] H. Kallmann, U. S. Army Signal Corps Report, December 1951 (unpublished).

Washington, October 11, 1956. 